without an excess of imagination. One of the most valuable aspects of the congress was that it provided an opportunity of revising fundamental notions borrowed from other branches of science which have been modified or invalidated by recent work.

The chairman of the congress was Dr. Fred Sargent, professor of physiology in the University of Illinois (who is now spending one year at the Medical Research Council Climate and Working Efficiency Research Unit in Oxford). Dr. J. L. Cloudsley-Thompson, of the Department of Zoology, King's College, London, was elected to the Council of the Society. The Society has begun publishing the International Journal of Bioclimatology and Biometeorology, and the proceedings of its first congress will appear in that journal. The second international congress of bioclimatology will be held in 1960, and England and Scotland have been mentioned as possible places for it. Information about the Society can be obtained from its secretary, Dr. S. W. Tromp, Hof brouckerlaan 54, Oegstgeest, Leyden, Holland, or from its representative in Great Britain, Dr. E. M. Glaser, Department of Physiology, London Hospital Medical College, Turner Street, E.1. Candidates for election must be actively engaged in some field of bioclimatology or biometeorology, they must be proposed by two members, and they must be approved by the Council. The business of the Society is trensacted mostly in English.

E. M. Glaser

\section{TRANSISTOR TECHNOLOGY}

A CONFERENCE on transistors, organized by the Electronics Group of the Institute of Physics, was held at the Brunel College of Technology, Acton, during September 27-28.

In almost every field of endeavour, the rate of progress largely depends on the facilities that exist for discussion and for exchanging information. This is particularly true when the available resources are scattered over a large number of industries, government and educational organizations, as is the case with the work on transistors. In the United States, professional societies and educational establishments seem to delight in organizing symposia and conferences, whereas in Britain there appears to be less inclination for activities of this kind; one hopes, therefore, that the success of this conference will provide a suitable stimulus to others.

Dr. M. E. Haine, chairman of the Electronics Group, explained that the topics had been chosen in such a way as to provide a broad picture of the wide range of activities that are embraced by transistor technology. Thus, the conference was less concerned with thrashing out points of detail than with providing an opportunity for those who are concerned with the details themselves to see a general picture.

The first paper, on "The Effect of Physical Properties of a Semiconductor on Device Characteristics", was given by Mr. D. D. Jones (General Electric Co.). In discussing the high-frequency performance of alloy transistors, he showed that the mobilities of both the majority and the minority carriers must be taken into account ; the relative merits of $n-p-n$ and $p-n-p$ structures largely depend on the degree of avalanche multiplication that is characteristic of the carrier- depletion regions of thin collector junctions. Mr. Jones indicated which physical properties are im. portant in the design of high-speed switching tran. sistors and of power transistors. He also discussed the relative merits of germanium and silicon as transistor materials.

In the next paper, Dr. W. Bardsley (Royal Radar Establishment) discussed "Defects in Transistor Materials", and, in particular, mentioned the effects of chemical impurities, particle bombardment, and dislocations in the crystal structure. A typical chemical defect, that can have a marked effect on the electrical performance of the semiconductor, is the presence of oxygen in silicon. Defects created by particle bombardment, for example, by means of neutrons, can often be removed by annealing. Dr. Bardsley described various techniques, such as etching and the use of X-rays, for revealing the presence of dislocations in crystals. Finally, he spoke of interactions between defects; thus interactions between dislocations and oxygen content can affect the heat treatment properties of silicon.

Mr. J. G. Cressell (Marconi) opened his paper on "Power Transistors" by recounting the main steps by which progress has been made in this field. First, there was Webster's analysis of the variation of current gain with emitter current, which showed how emitter efficiency, bulk recombination and surface recombination play their part. The development of new alloys to give high emitter efficiency and of techniques to produce thin base regions were two practical steps of major importance. Fletcher's study of the transverse field in the base region led to a reconsideration of the optimum geometrical arrangement. Mr. Cressell then described how both carrier life-time and surface recombination velocity can show substantial variations with emitter current, and how these effects become important in high-power transistors.

The design of high-frequency transistors presents a considerable challenge. In describing "A New High-frequency Germanium Transistor", Mr. J. S. Lamming (General Electric Co.) first discussed the principle of Kroemer's drift transistor; in this a gradation in the conductivity of the base region creates a drift field which reduces the transit-time for minority carriers. One of the most attractive ways of producing a graded base region is to diffuse the impurity atoms into the region. In Mr. Lamming's technique of 'post-alloy diffusion' the emitter is alloyed on to a base region of uniform conductivity. The emitter alloy is made to contain known quantities of $p$ and $n$ impurities, the segregation and diffusion coefficients of which are carefully chosen. After alloying, the emitter is $p$-type. The structure is then heated to such a temperature that diffusion takes place, the coefficients being such that the diffusion is predominantly that of the $n$ impurities. This technique enables very narrow base regions, with the desired gradation of conductivity, to be achieved.

Dr. J. T. Kendall (Texas Instruments) reviewed the situation of "Silicon Transistors". He mentioned how the difficulty in producing silicon of adequate purity and of keeping it pure during subsequent processing had delayed the development of these devices. The alloy process, so successful with ger. manium, had proved difficult with silicon and, as a result, most of the progress has been achieved with other processes, such as double-doping during crystal 
growing, grown-diffusion, melt-back diffusion, and double-diffusion. Dr. Kendall also made an objective comparison of silicon and germanium transistors, stressing the advantages of the former in hightemperature applications.

In $\mathrm{a}_{\mathrm{e}}$ conference where one often heard of the need for semiconductor materials of high quality, it was interesting to hear of some of the chemist's difficulties in Mr. J. M. Wilson's (Standard Telephone Laboratories) paper on "The Preparation of Very High Purity Silicon". The high segregation coefficient of boron makes it very difficult to purify by means of the zone-refining technique, which has been used so successfully with germanium. After reviewing a number of methods, Mr. Wilson described his work on a process which starts with the thermal decomposition of silane $\left(\mathrm{SiH}_{4}\right)$. The silicon can be produced in a crystalline form without having to use crucibles; this feature is attractive in view of the high reactivity of silicon with the crucible materials.

Dr. A. F. Gibson (Royal Radar Establishment) dealt with "Avalanche Injection" and the possibility of utilizing it in certain devices. When the field across a filament of $n$-type germanium exceeds a critical value, avalanche multiplication gives rise to a rapid inerease in conductivity; as a result, the voltage-current characteristic exhibits a negative resistance region, similar to that obtained with a gas discharge tube. In order to limit the current, and hence the dissipation, in the high-current condition, the area of one of the contacts to the germanium is made small. Dr. Gibson then discussed a device, having two $n+$ contacts and one $p+$ contact to the germanium, which is analogous to the thyratron, and in which the current flowing into the $p+$ contact controls the voltage-current characteristic at the other two.

Dr. D. F. Taylor (Ferranti), in a paper on "Improved Junction Fabrication", dealt mainly with the problems of making alloyed junctions in silicon. $\mathrm{He}$ considered the conditions that are necessary for regrowth to take place. $\mathrm{He}$ showed that, when alloying an aluminium wire to a silicon wafer, if, during the cooling cycle, the wire is maintained at a higher temperature than the molten region no regrowth takes place; Dr. Taylor suggested that the reason why good diode characteristics are obtained under these conditions is that diffusion takes place at the alloy/silicon interface during the alloying. Finally, he considered some aspects of the 'limited' type of alloy process, such as takes place when a small 'dot' is alloyed to a silicon wafer.

The last paper in the conference was given by $\mathrm{Dr}$. M. Smollett (Mullard), whose subject was "Germanium Photo-transistors". After considering the creation of hole-electron pairs in germanium when light shines on it, he described the photo-electric properties, including the spectral response, of a $p-n$ junction diode in which the $p$-region is made very thin. He then analysed the operation of the phototransistor, which differs from the diode in that it can produce substantial multiplication of the current that is produced by the holo-electron pairs that are generated by the incident light. Possibly their main disadvantage is the fact that hole-electron pairs produced by thermal agitation also contribute to the output current; Dr. Smollett indicated ways of minimizing this.

Each paper was followed by a discussion, during which many useful and stimulating comments were made.

\section{HERRING IN THE NORTH SEA}

$I^{N}$

1955 the East Anglian herring fishery failed. This is a drift-net fishery which exploits different populations during October and November, and its success is to a large extent dependent on the dates of the full moons which, though not propitious for the 1955 season, could not possibly provide the complete reason for the failure. However, several changes had taken place since the Second World War. In 1948 the Danes started trawling for young immature herring and they were followed by the Germans, Dutch and French. These 'industrial' herrings were used for processing into fish meal. While the catches were at first insignificant they increased enormously during the following seven years until the number of herrings trawled far outnumbered those caught during the East Anglian fishery. Another rapid development since 1951 was the trawl fishery for adult herring in the Channel and North Sea Southern Bight by German, French, Duteh, Belgian, Polish and Icelandic fishermen. The landings from this new fishery have led to what might appear to be a shift from the fish being landed by drifters to being landed by trawlers. Coincident with these changes in the fisheries there have been changes in the environment (for example, the amount of food (Calanus) available) and in the biological characters of the herrings (as, for example, the mean length at various ages and, apparently, age at first maturity).

In a recent fishery investigation, published under the title "On the Herring of the Southern North Sea"*, Dr. D. H. Cushing and Mr. A. C. Burd have attempted to sort out these complexities, about which fishery biologists and fishermen have strong and divided views.

Their paper consists of four parts, the first of which, by Dr. Cushing, is concerned with the homogeneity and character of the Southern Bight stocks. In the second part he considers the natural changes that have occurred in the populations, changes among others, in age distribution, length, nature of recruitment, in the environment and in the fishery. Part 3, by Mr. Burd, discusses the changes that can be ascribed to fishing, while in the last section Dr. Cushing considers the effect of fishing on the stock. It is impossible in a review of this length to discuss their evidence in detail, but it leads them to believe that, through the advance in maturity, the fish are caught sooner in their life and this reduces the older age-groups which, together with the southern North Sea and Channel trawl fishery, reduces the November East Anglian catches of older fish. The danger caused by 'industrial' fishing of immature herrings receives a verdict of 'not-proven'. These conclusions should be put in perspective by pointing out that Dr. W. C. Hodgson, and many of the fishermen themselves, believe that this 'industrial' fishing to the north provides at least part of the explanation of the failure, and probably a large part.

Perhaps the wisest words in this paper are in Mr. Michael Graham's preface: "Dogmatism is out of place in this subject, ... and in addition, data on highly migratory fisheries are always difficult to interpret".

T. B. BAGENAL

* Ministry of Agriculture, Fisheries and Food. Fishery Investigations. Series 2, Vol. 20, No. 11: On the Herring of the Southern North Sea. By D. H. Cushing and $A$. C. Burd. Pp. iv +31 . (London: H.M. Stationery Office, 1957.) 8s. $6 d$. net. 